\title{
Stage IV Primary Peritoneal Cancer AJCC v7
}

National Cancer Institute

\section{Source}

National Cancer Institute. Stage IV Primary Peritoneal Cancer A/CC V7. NCI Thesaurus. Code C115098.

Stage IV includes: Any T, Any N, M1. M1: Distant metastasis (excludes peritoneal metastasis). (AJCC 7th Ed.) 